\title{
Analysis of Double Front Suspension for Mining Truck
}

\author{
Lijun Zhao ${ }^{\mathrm{a}}$, Ying $\mathrm{Li}^{\mathrm{b}}$, and Jing $\mathrm{Pei}^{\mathrm{c}}$
}

School of Automobile Engineering, Harbin Institute of Technology at Weihai, Weihai 264209, China. a315926038@qq.com, b liying_0414@126.com, ${ }^{c}$ peijingwh@163.com

Keywords: mining truck; front suspension; statics analysis; modal analysis.

\begin{abstract}
As an important transportation tool of earth stone, mining truck withstand the impact of complex alternating dynamic load. Suspension as a connection of frame and axle, reduce the impact effectively. The double arm independent suspension was regarded as the research object in this paper, and analyzed to the key components with the finite element. The static force of the steering knuckle was analyzed by force and moment balance, and the finite element model was established based on ANSYS. The static and modal was analyzed, the results show that the design requirements are satisfied.
\end{abstract}

\section{Introduction}

As an important transportation tool of earth stone, mining truck is widely used in mining, metallurgy, construction, chemical engineering, municipal and other industries, the development and manufacture of a more reliable and higher performance of the mining truck is necessary, the mine vehicle have higher requirements on handling stability ${ }^{[1][2]}$. The double wishbone independent front suspension applied, and the driving comfort improve to some extent ${ }^{[3]}$.

Therefore, based on the previous research, we analyzed structural static and modal for the independent front suspension of the key components Using ANSYS, to ensure the structure can satisfy the design requirements of the strength, stiffness and stability, improved the handling stability and ride comfort for mining vehicle.

\section{Static Force Analysis}

As the key part of the front suspension, the steering knuckle is complicated. Before the finite element analysis, the role of the important parts in the suspension of the bearing capacity calculated according to the ground effect on the wheel of each reaction ${ }^{[4]}$. And the stress of the steering knuckle in the transverse and longitudinal plane of the mining truck as shown in Figure 1:
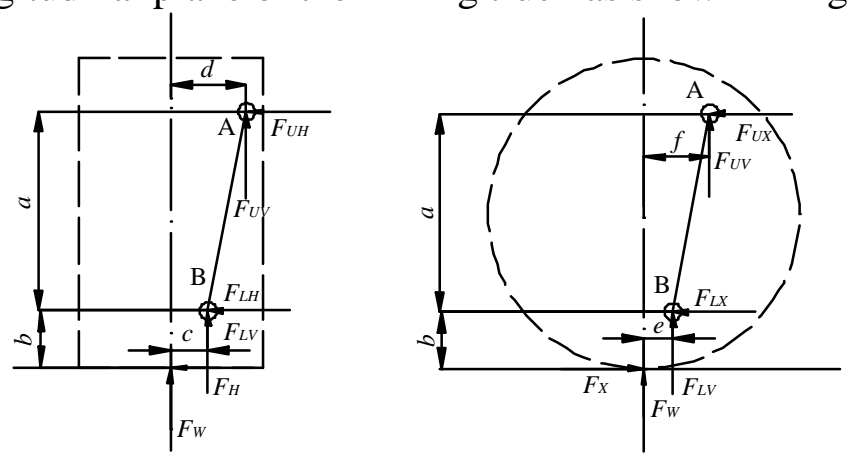

Figure 1 The stress of the steering knuckle in the transverse and longitudinal plane

The force analysis in the transverse plane can be introduced by the force balance and torque balance $^{[5]}$ :

$$
\left\{\begin{array}{l}
F_{W}+F_{L V}+F_{U V}=0 \\
F_{W} d+F_{H}(a+b)+F_{L V}(d-c)+F_{L H} a=0
\end{array}\right.
$$

Where, $F_{W}$ is the normal force of face on tire, $(\mathrm{N}) ; F_{H}$ is the lateral force of face on tire, $(\mathrm{N}) ; F_{L V}$ is the normal force of under the arm on the knuckle, $(\mathrm{N}) ; F_{U V}$ is the normal force of upper the arm on the 
knuckle,(N); $F_{L H}$ is the lateral force of under the arm on the knuckle,(N); $F_{U H}$ is the lateral force of upper the arm on the knuckle,(N); $a$ is the vertical distance of $A$ and $B,(\mathrm{~mm}) ; b$ is the vertical distance of $B$ and ground,(mm); $c$ is the lateral distance of $B$ and wheel longitudinal plane center, $(\mathrm{mm}) ; d$ the lateral distance of $A$ and wheel longitudinal plane center, (mm).

The force analysis in the longitudinal plane can be introduced:

$$
\left\{\begin{array}{l}
F_{U X}+F_{L X}-F_{X}=0 \\
-F_{W} e+F_{X} b+F_{U X} a+F_{U V}(f-e)=0
\end{array}\right.
$$

Where, $F_{X}$ is the longitudinal force of face on tire, acceleration for driving, brake for braking ,(N); $F_{L X}$ is the longitudinal force of under the arm on the knuckle, $(\mathrm{N}) ; F_{U X}$ is the longitudinal force of upper the arm on the knuckle, $(\mathrm{N}) ; e$ is the longitudinal distance of $B$ and the wheel plane, $(\mathrm{mm}) ; f$ is the longitudinal distance of $A$ and the wheel plane, (mm).

The force analysis in the horizontal plane can be introduced:

$$
\left\{\begin{array}{l}
F_{H}+F_{L H}+F_{U H}=0 \\
F_{X} c+F_{U X}(d-c)+F_{U H}(f-e)=0
\end{array}\right.
$$

Form the formula (1) - (3) and other relevant data of front suspension, the force on the hem arm and steering knuckle ball hinge joint premises can be obtained.

\section{Structural static analysis}

In this paper, the strength and stiffness of the steering knuckle are analyzed by using ANSYS.

Geometry Modeling. The suspension steering knuckle model established by CATIA, and import into ANSYS directly.

Material Properties. The material selected HG70 (high strength welded structural steel) for steering knuckle, considering the safety and fatigue durability, and the parameters are shown in Table 1.

Table 1 material parameters of steering knuckle

\begin{tabular}{cc}
\hline Material Property & Parameter Value \\
\hline Modulus of elasticity $E(\mathrm{GPa})$ & 210 \\
Density $\rho(\mathrm{kg} / \mathrm{m} 3)$ & 7900 \\
Poisson ratio $u$ & 0.3 \\
Yield limit $\delta s(\mathrm{MPa})$ & 550 \\
Tensile strength $\delta_{b}(\mathrm{MPa})$ & 680 \\
\hline
\end{tabular}

Meshing and boundary. The tetrahedral element and adaptive mesh was selected, and the grids as shown in Figure 2.

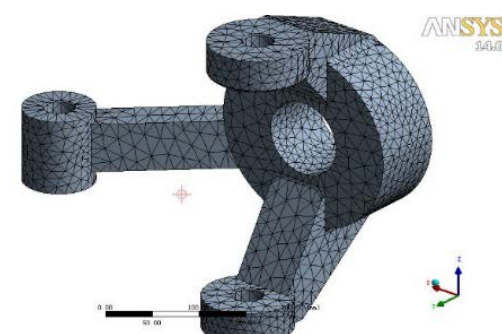

Fig. 2 The element of steering knuckle

We select a safety factor of 2, considering the tire not bear the lateral and longitudinal force from the ground in the static structure analysis, and supposed that the ground vertical reaction force is 2 times of the weight to mining trak, that $F_{W}$ is $2.5 \times 10^{5} \mathrm{~N}$.

The load under the Deputy Commissioner of the ball of steering section can be calculated from (1) (3), we can found that the steering knuckle is mainly subjected to the vertical force, the second is the transverse force, and the last is the longitudinal force when the vehicle is stationary. All loads are applied in the form of a concentrated force. The displacement as boundary condition in this paper. And the hole groove in the middle of the steering knuckle is mainly matched with the bearing, which imposed constraint on the circumferential surface of the hole. 
Result Analysis. The results of the static analysis of the steering knuckle are shown in figure 3 5.

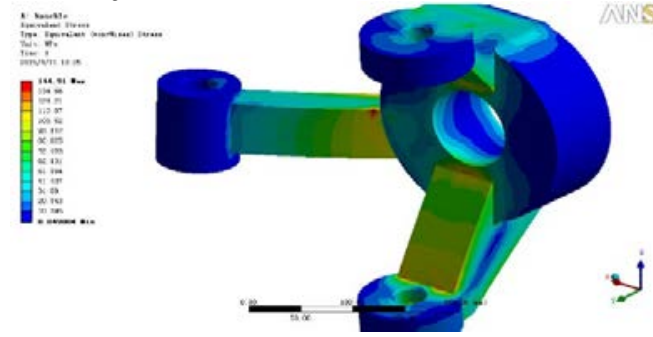

Fig. 3 The stress of steering knuckle
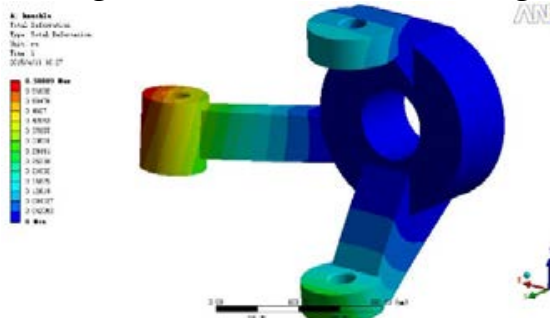

Fig. 4 The deformation of steering knuckle
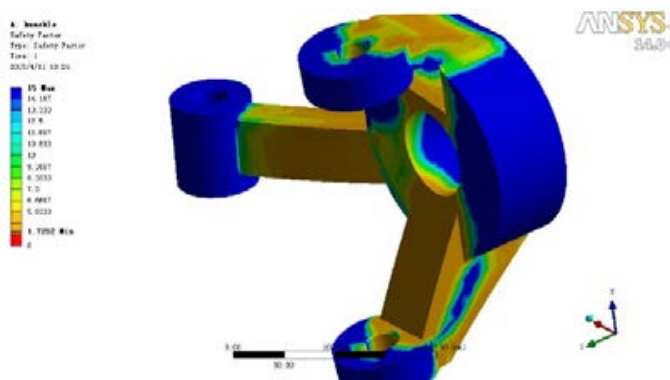

Fig. 5 The safety factor of steering knuckle

As we can see from figure 3 5, the biggest stress for steering Festival is $145 \mathrm{MPa}$, less than the material yield limit 550Mpa. The maximum deformation is $0.6 \mathrm{~mm}$ and appeared in the end of the steering knuckle arm which is hinged with the transverse rod, and the structure is safety, our design of steering knuckle structure met the requirements.

\section{Modal Analysis and Result}

Mining truck subjected to dynamic loading, if the natural frequency of steering knuckle and road excitation frequency too close, and resonance induced, affecting ride comfort and safety, so it is necessary to modal analysis for steering knuckle.

Considering the effect of high frequency vibration mode on structure in engineering practice is very small, the Block Lanczos mode extraction method selected, and only extracted the first six order modes, and the frequency is less than $2000 \mathrm{~Hz}$. The first six order mode of the steering knuckle analyzed by ANSYS as shown in figure $6 \sim 11$.

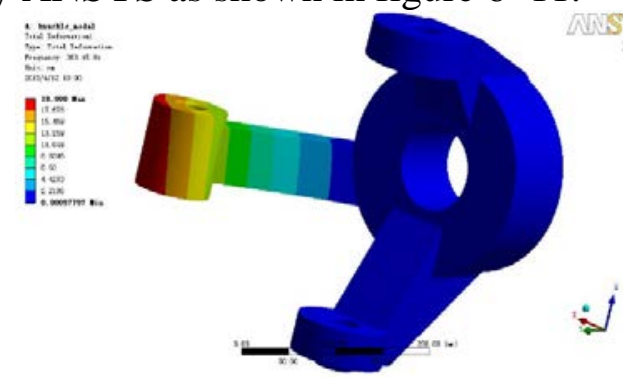

Fig. 6 The one order mode of steering knuckle

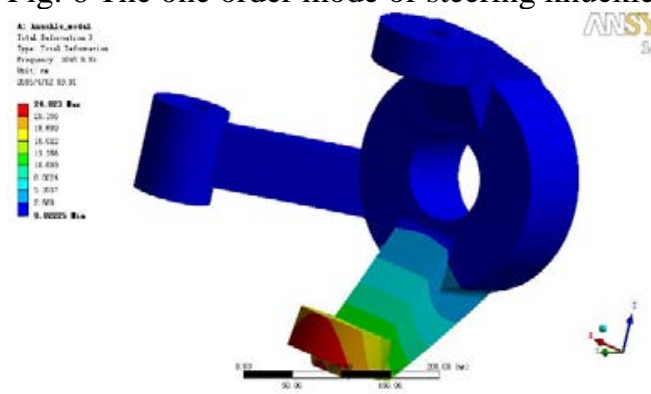

Fig. 8 The three order mode of steering knuckle Fig. 9 The four order mode of steering knuckle
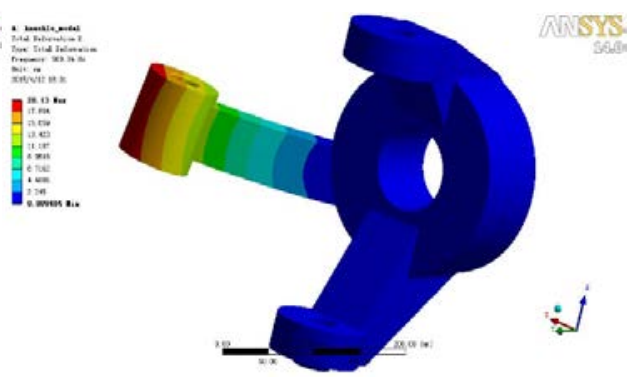

Fig. 7 The two order mode of steering knuckle
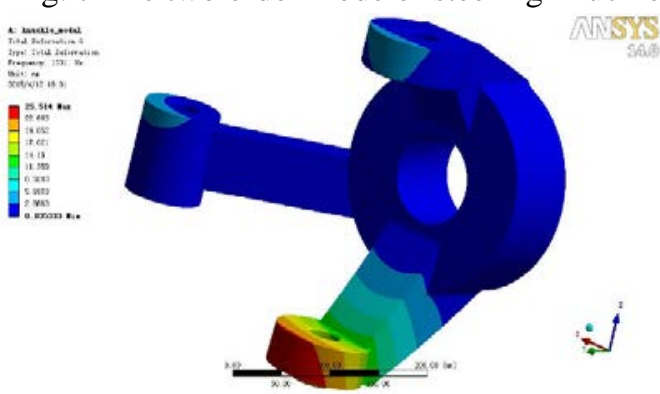


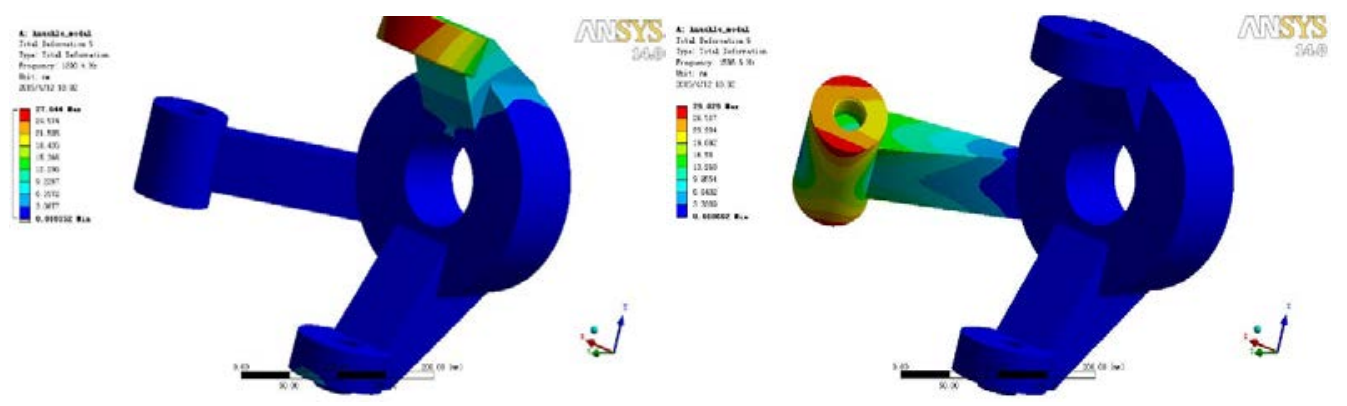

Fig. 10 The five order mode of steering knuckle Fig. 11 The six order mode of steering knuckle

According to the results, the natural frequency of the steering section corresponding to the mode of vibration described as shown in table 2.

Table 2 the description of steering knuckle

\begin{tabular}{ccc}
\hline Order & Natural Frequency $(\mathrm{Hz})$ & Modal Description \\
\hline 1 & 383.45 & Steering knuckle arm end swing on $X Y$ direction \\
2 & 509.34 & Steering knuckle arm end swing on $Z$ direction \\
3 & 1048.8 & Steering knuckle under ball swing on $Z$ direction \\
4 & 1331 & Steering knuckle under ball swing on $X$ direction \\
5 & 1390.4 & Steering knuckle upper ball swing on $Z$ direction \\
6 & 1586.6 & Steering knuckle arm twisted along its axis \\
\hline
\end{tabular}

Combined suspension system frequency characteristic analysis, there are two formant frequencies evaluation index of suspension caused by uneven road excitation, respectively for $1.19 \mathrm{~Hz} 14.86 \mathrm{~Hz}$, and the natural frequency of the steering knuckle is above $380 \mathrm{~Hz}$, so it is obvious that the front suspension will not cause the steering knuckle resonance due to the uneven road surface.

\section{Summary}

In this paper, the stress of the front suspension steering knuckle analyzed based on the static knowledge, and analyzed the steering knuckle of static strength, stiffness and modal analysis with ANSYS, the results show that the strength is less than the material yield limit, and the lowest order natural frequency of the steering knuckle is much higher than the resonance frequency caused by road excitation, so the design of the suspension not destroyed caused by resonance driving in various conditions. The research provides a theoretical reference for the dynamic and experimental design of the follow-up mining truck.

\section{References}

[1] Ahmadian Mehdi. Integrating Electromechanical Systems in Commercial Vehicles for Improved Handling, Stability, and Comfort[J]. SAE International Journal of Commercial Vehicles, 2014, 7(2): 76-87.

[2] Vantsevich Vladimir V. Vehicle systems: Coupled and interactive dynamics analysis[J]. Vehicle System Dynamics, 2014, 52(11): 1489-1516.

[3] Giancarlo Genta, Lorenzo Morello. The Automotive Chassis[M]. Springer: MECHANICAL ENGINEERING SERIES, 2008. 133-261.

[4] Mosayebi Masoud, Pourshams Mohammad, Keshavarzi Ahmad. Optimization of double wishbone suspension system with variable camber angle by hydraulic mechanism[J]. World Academy of Science, Engineering and Technology, 2010, 37(11): 299-306.

[5] Jagirdar V.V., Dadar M.S., Sulakhe, V.P.. Wishbone structure for front independent suspension of a military truck[J]. Defence Science Journal, 2010, 60(2): 178-183. 